УДК 53.05

DOI: https://doi.org/10.17308/kcmf.2019.21/764

Поступила в редакцию 10.05.2019

Подписана в печать 15.05.2019

\title{
ПРИМЕНЕНИЕ СИНХРОТРОННОЙ ИК-МИКРОСПЕКТРОСКОПИИ ДЛЯ АНАЛИЗА ИНТЕГРАЦИИ БИОМИМЕТИЧЕСКИХ КОМПОЗИТОВ С НАТИВНОЙ ТВЕРДОЙ ТКАНЬЮ ЗУБА ЧЕЛОВЕКА
}

\author{
2019 П. В. Середин ${ }^{1 凶}$, Д. Л. Голощапов ${ }^{1}$, В. М. Кашкаров ${ }^{1}$, К. А. Никитков ${ }^{1}$, В. Н. Бартенев ${ }^{1}$, \\ Ю. А. Ипполитов ${ }^{2}$, Jitraporn (Pimm) Vongsvivut ${ }^{3}$
}

${ }^{1}$ Воронежский государственный университет Университетская пл., 1, 394018 Воронеж, Российская Федерация

${ }^{2}$ Воронежский государственный медицинский университет им. Н. Н. Бурденко Студенческая ул., 10, 394036 Воронеж, Российская Федерация

${ }^{3}$ Australian Synchrotron (Synchrotron Light Source Australia Pty LTD) 800 Blackburn Rd Clayton, VIC 3168, Australia

\begin{abstract}
Аннотация. В данной работе продемонстрирована возможность применения ИК-микроспектроскопии для многомерной визуализации и анализа интеграции с нативными твердыми тканями зуба человека нового поколения биомиметических материалов, воспроизводящих минералорганический комплекс эмали и дентина.

На основе ИК-картирования интенсивности конкретной функциональной молекулярной группы с использованием синхротронного излучения найдены и визуализированы характеристические особенности биомиметического переходного слоя в межфазной области эмаль/стоматологический материал и определено расположение функциональных групп, отвечающих процессам интеграции биомиметического композита.
\end{abstract}

Ключевые слова: биомиметические материалы, нативная твердая ткань зуба человека, ИК-микроспектроскопия, синхротронное излучение.

\section{ВВЕДЕНИЕ}

На современном этапе развития стоматологического материаловедения восстановление анатомической основы зуба человека или его части осуществляется с использованием цементов и пломбировочных материалов, которые имеют низкое сродство с эмалью и дентином зуба $[1,2]$. Следствием данного факта является неудовлетворительная адгезия и возникновение вторичного кариеса на границе пломба/эмаль зубов [2]. Поэтому востребованной задачей в стоматологии является улучшение интеграции применяемого или разрабатываемого материала с зубным матриксом $[1,3]$. Одновременно с этим активно изучается взаимодействие синтетического материала с тканями зуба, а также формирование биомиметического переходного слоя на межфазной границе между естественной твердой тканью зуба и стоматологическим композитом [2-5], который должен выступать

$\triangle$ Середин Павел Владимирович, e-mail: paul@phys.vsu.ru связующим звеном между двумя гетерогенными материалами.

Учитывая, что дентин и эмаль являются биологическими структурно организованными нанокристаллическими композитами с мезо- и нанопористой структурой, обладающими анизотропией механических, оптических и трофических характеристик [6], то создание стоматологического синтетического материала схожей конфигурации является неординарной и чрезвычайно сложной проблемой [7]. Поэтому в настоящее время активно развивается биомиметический подход к реставрации и регенерации утраченных твердых тканей зубов для минимизации сколов, истирания, эрозии и развития кариеса на границе биокомпозит/ткани зуба [810]. В рамках данной концепции для процессов восстановления и воссоздания твердой зубной ткани предполагается использование материалов, которые по своему молекулярному составу, химическим и морфологическим характеристикам имеют максимальное родство естественно- 
му апатиту эмали и дентина, а также их аминокислотному матриксу [8, 10-12]. Современные материалы для стоматологии, учитывающие состав нативных тканей зубов человека, обязательно включают в себя нанокристаллический гидроксиапатит (ГАП) кальция с различной дефектной структурой в нем $[7,13,14]$. Кроме того, обязательным условием при создании такого рода материалов является включение в их состав различного типа органической составляющей для улучшения механических, адгезивных и прочностных характеристик [15-17].

Следует отметить, что с использованием принципа биомиметики многократно были предприняты попытки воспроизведения органоминерального комплекса зубов и создания у композитов эмале- и дентиноподобной структуры [10, 18-21]. В самых последних из известных работ биокомпозиты были созданы путем синтеза ГАП в присутствии различных полимеров и аминокислотных составляющих, а также ПАВ и высокомолекулярных соединений [15, 22-24]. Эта идея основана на фундаментальных принципах взаимодействия материалов и используется для достижения морфологической однородности и гомогенного распределения нанокристаллов ГАП на поверхности полимерной и органической матрицы. Рассматриваемая проблема по синтезу родственных эмали/дентину биомиметических материалов включает не только фундаментальные вопросы технологии получения биокомпозитов $[12,25,26]$, но и задачи об установлении органоминерального взаимодействия между естественной тканью и созданного по её подобию биоматериала [12, 27, 28]. Поэтому необходимы и востребованы прецизионные исследования как биогенных образцов эмали и дентина, так и процессов, происходящих в синтетических аналогах нативных материалов, а также изучение взаимодействия на межфазных границах стоматологический материал/биомиметический композит/твердая ткань зуба человека.

Одним из методов, зарекомендовавших себя при исследованиях биологических объектов, является инфракрасная Фурье спектроскопия (FTIR) [29-32]. Преимуществом данного метода является высокая избирательность и чувствительность: метод позволяет получить обширные и разнообразные сведения о молекулярном составе различных тканей зубов человека [30, 33], исследовать механизмы молекулярных превращений, происходящих в биомиметических материалах, регистрировать новообразованные минеральные фазы [34, 35]. К достоинствам ИК-спектроскопии также можно отнести возможность использования её при анализе многокомпонентных стоматологических материалов [30]. В отличие от ряда других подходов при использовании методики FTIR изучаемая система подвергается слабым внешним воздействиям, поэтому полученная информация относится к системе, не претерпевшей изменений в результате этих взаимодействий [31]. Одновременно с этим включение в измерительную схему микроскопа, а также использование источника синхротронного излучения при исследованиях биологических объектов позволяет собрать большие массивы спектров с микрообласти образца за короткое время. Это дает возможность сформировать ИК-спектроскопическое мозаичное изображение образца, одновременно богатое различной информацией о молекулярной химии, составе и структуре исследованных гетерогенных образцов. Использование синхротронной ИК-спектромикроскопии уже позволило нам достигнуть необходимого спектрального разрешения и достоверно определить изменения, происходящие в молекулярном составе образцов, в случае кариеса [32, 36]

Поэтому целью данной работы стало исследование молекулярно-химических особенностей формирования интерфейса стоматологический материал - биомиметический композит - твердая ткань зуба с использованием подхода многомерной визуализации данных синхротронной ИК-микроспектроскопии.

\section{ЭКСПЕРИМЕНТАЛЬНАЯ ЧАСТЬ}

Методика подготовки материалов

Изучение буферных слоёв биокомпозиционных материалов и определение условий возникновения устойчивых функциональных связей на границе биомиметический материал/естественная твердая ткань производилось на образцах зубов, удалённых у пациентов в возрасте 18-45 лет по ортодонтическим показаниям. Образцы зубов с начальным фиссурным кариесом во избежание протекания долговременных процессов обызвествления и кальцификации немедленно препарировались с использованием утверждённых стандартов и в соответствии с диагностированной патологией. Во всех образцах формирование полости в эмали производилось до дентина с использованием водяного охлаждения для исключения перегрева зубного матрикса. На поверхность полученной полости наносилась биокомпозиционная буферная система, включающая нанокристаллический карбонат-замещенный гидроксиапатит кальция 
(КГАП), соответствующий по совокупному ряду характеристик апатиту эмали и дентина человека $[37,38]$ и ряд аминокислот, присутствующих в составе органического матрикса эмали и дентина: L-гистидин, L-лизин гидрохлорид, L-аргинин гидрохлорид и гиалуроновую кислоту. Соотношение составляющих было выбрано аналогично их содержанию в составе эмалевого матрикса [39]. При фиксации полученной буферной системы использовался универсальный адгезив для биоактивной бондинговой системы, показавший эффективное связывание с разработанными коммерческими материалами [40]. Для заполнения дефектов и улучшения связывания с твёрдыми тканями зуба в адгезив был внесен полученный в данной работе КГАП. Универсальный светоотверждаемый адгезив, содержащий КГАП наносился на поверхность буферного слоя и подвергался предварительной фотополимеризации в течение 20 секунд. По истечении 1 минуты на сформированный биокомпозиционный связующий слой наносился коммерческий компомерный реставрационный материал Dyract XP, содержащий компоненты адгезива. После этого нами были подготовлены плоскопараллельные сегменты образцов отреставрированных зубов по методике указанной в $[41,42]$.

Полученные шлифы были изучены методом ИК-спектромикроскопии с привлечением оборудования канала Инфракрасной Микроспектроскопии (IRM) (Австралийский синхротрон, Мельбурн, Австралия), имеющего в своем составе ИК- спектрометр Bruker Vertex 80V, сопряжённый с ИК-микроскопом Hyperion 3000 с детектором, oxлаждаемым жидким азотом (Bruker Optik GmbH, Ettlingen), Германия) [31]. На рис. $1 a$ представлена призма НПВО и приставка НПВО, с использованием которой осуществлялось картирование выделенной области исследуемых биологических объектов на ИК-микроскопе Hyperion 3000 (рис. $1 b)$. Размер исследуемой области ограничивался размером призмы и составлял $250 \mu \mathrm{m}$. Полученные ИК-спектры поглощения были зарегистрированы в области от $3800-700 \mathrm{~cm}^{-1}$ при спектральном разрешении $4 \mathrm{~cm}^{-1}$.

С использованием макро ATR-FTIR приставки (рис. 1a) на Австралийском источнике синхротронного излучения были исследованы участки межфазной границы стоматологический материал/биомиметический композит/эмаль и составлены ИК-карты интенсивности конкретной функциональной молекулярной группы для участка интеграции стоматологического материала и эмали зубов (рис. $1 b$ ) по алгоритмам представленным в работе [31].

На рис. $2 a$ приведено оптическое изображение плоскопараллельного сегмента исследуемого образца, участок эмали которого был восстановлен с использованием биомиметического композита. Прямоугольной областью на рис. $2 a$ обозначена зона межфазной границы стоматологический материал/биокомпозит/эмаль. $20 \times$ оптическое изображение данной области гетерофазной границы представлено на рис. $2 b$.
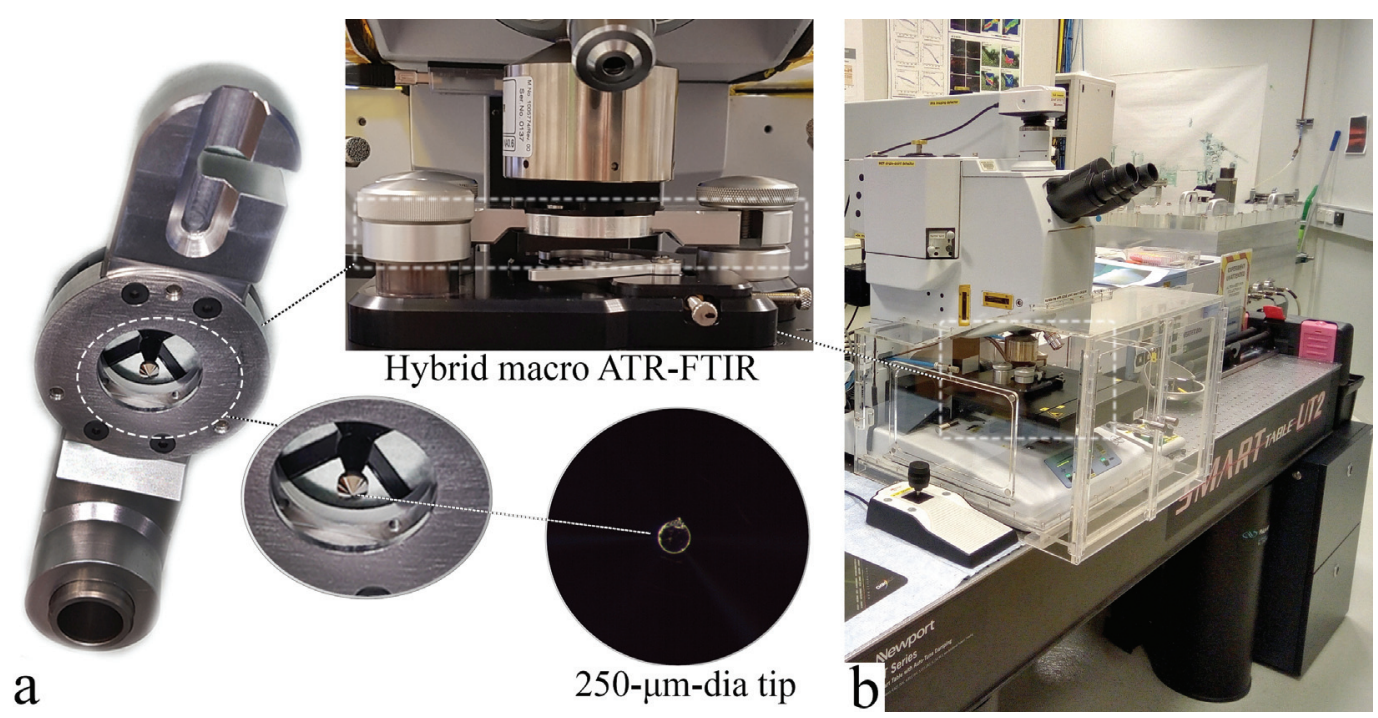

Рис. 1. Элементы призмы нарушенного полного внутреннего отражения для макро исследований (макро ATR-FTIR), с использованием которой осуществлялось картирование образцов (a) и общий вид ИК-микроскопа Hyperion 3000 (b)

[Fig. 1. Elements of the attenuated total reflection prism for macro studies (macro ATR-FTIR), which was used for samples mapping (a) and the general view of a Hyperion 3000 IR microscope $(b)$ ] 

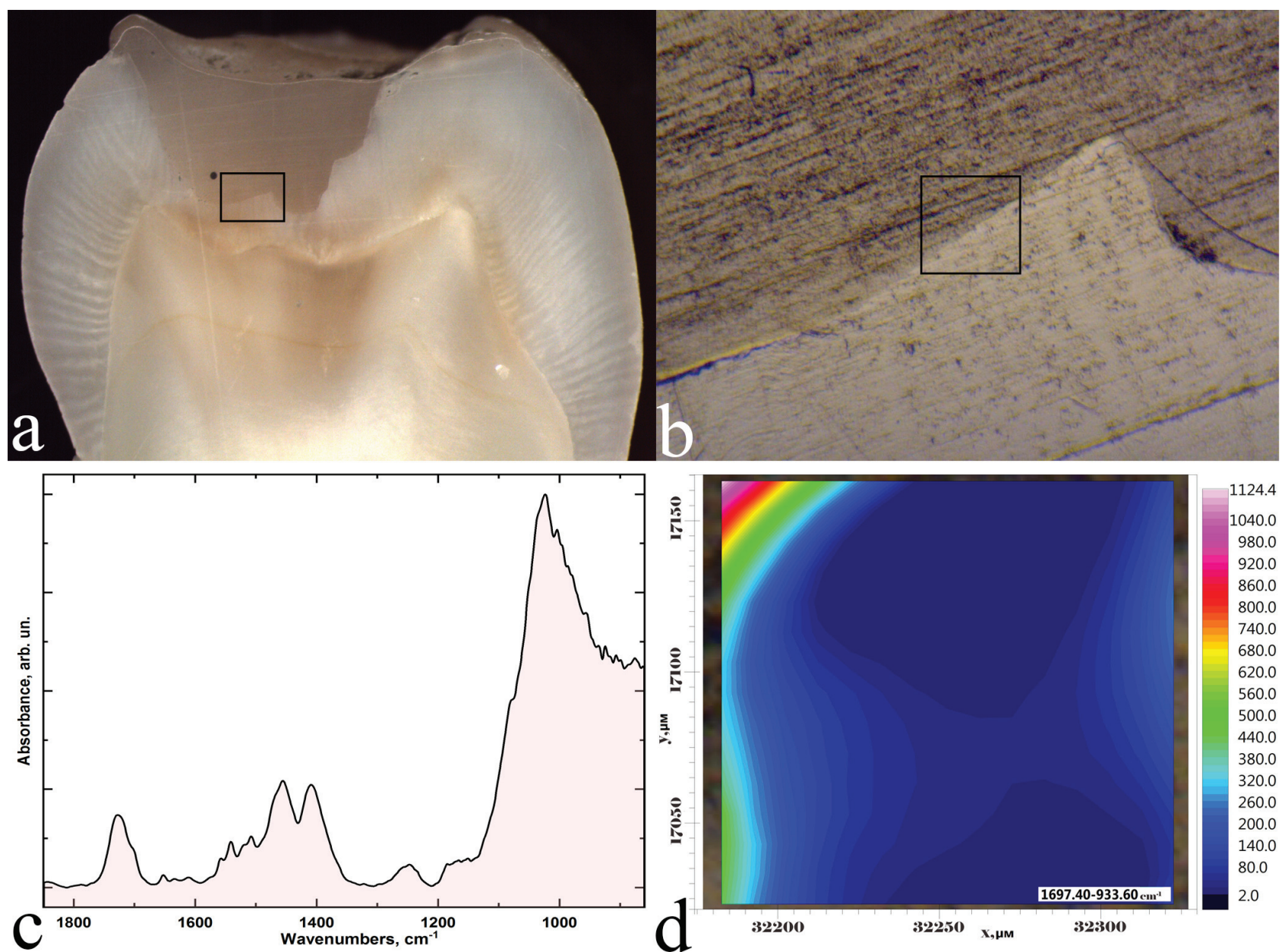

Рис. 2. Изображение образца зуба человека (a) с участком 100×100 $\mu \mathrm{m}$, содержащим участок межфазной границы со светоотверждаемым стоматологическим материалом/биомиметическим композитом/эмалью $(b)$ от которого был получен массив спектров, включая типичный ИК-спектр поглощения из области межфазной границы (c) - и по которому составлена ИК-карта общего поглощения $(d)$

[Fig. 2. Image of a sample of a human tooth $(a)$ with a $100 \times 100 \mu \mathrm{m}$ section containing the interphase border of a light-cured dental material / biomimetic composite / enamel (b) from which an array of spectra was obtained, including typical infrared absorption spectrum from the interface region $(c)$ and from which an IR map of total absorption was constructed $(d)]$

Видимая часть рассматриваемого участка границы стоматологический материал/биомиметический композит/эмаль определялась размером окна призмы macro ATR-FTIR и составляла $250 \mu \mathrm{m}$, при этом размер анализированной области составил $100 \times 100 \mu \mathrm{m}$, что схематично показано на рис. $2 b$.

В ходе исследования участка межфазной границы светоотверждаемый стоматологический материал/биомиметический композит/эмаль был определен набор основных колебательных мод в ИК-спектре, которые могут выступать в роли спектроскопических сигнатур молекулярных групп, отвечающих материалам, присутствующих в области интеграции. Характеристический ИК-спектр поглощения, полученный из обоз- наченной области на поверхности образца, приведен на рис. $2 c$. Основные полосы, наблюдаемые в спектре, относятся группе эфира $\left(-\mathrm{COOCH}_{3}\right)$, присутствующего в составе стоматологического материала на основе БИС-ГМА $\left(1725 \mathrm{~cm}^{-1}\right)$ [30], молекулярным группам $\mathrm{CH}_{2}-\mathrm{CH}_{3}\left(1457 \mathrm{~cm}^{-1}\right)$ и амидным полосам $\left(1650 \mathrm{~cm}^{-1}\right.$ (Amid I), $1550 \mathrm{~cm}^{-1}$ (Amid II) и $1240 \mathrm{~cm}^{-1}$ (Amid III)), входящих как в состав биомиметического композита, так и нативной ткани, а также к неорганической составляющей апатита эмали и биокомпозита (группа $\mathrm{PO}_{4}$ в области $900-1100 \mathrm{~cm}^{-1}$ ). На рис. $2 d$ представлена ИК-карта полного поглощения образца в области интерфейса стоматологический материал/биомиметический композит/эмаль. Как видно из представленного изображения полно- 
го ИК-поглощения, на карте нет морфологической/молекулярной информации. Данная ИК-карта отображает лишь цветовое кодирование интенсивностей основных полос в спектрах поглощения из различных точек поверхности образца, где присутствуют те или иные химические компоненты.

\section{РЕЗУЛЬТАТЫ И ИХ ОБСУЖДЕНИЕ}

Характеристические ИК-спектры от каждой из исследуемых зон в области границы стоматологический материал/биомиметический композит/эмаль, полученные с использованием синхротронной ИК-микроспектроскопии, представлены на рис. $3 a, 4 a, 5 a$. Каждый спектр содержит спектроскопические сигнатуры молекулярных групп материалов, присутствующих в области интеграции.

На рис. $3 b, 4 b, 5 b$ приведены одномерные изображения (ИК-карты), полученные на основе цветового кодирования интенсивностей трех основных спектральных полос $\left(1725 \mathrm{~cm}^{-1}, 1240\right.$ $1650 \mathrm{~cm}^{-1}$ и $\left.900-1100 \mathrm{~cm}^{-1}\right)$. Эти карты несут информацию о пространственном распределении стоматологического материала, органической и минеральной (апатит) составляющих на исследованном участке образца в области границы стоматологический материал/биомиметический композит/эмаль. Синим цветом закодирована самая низкая интенсивность поглощения конкретной молекулярной группы, в то время как красным показана самая высокая.

На рис. $3 a$ представлен ИК-спектр, полученный из области эмали образца (нижняя правая часть участка интеграции биомиметического материала с эмалью зубов рис. $2 b$ ). Выделенный в спектре диапазон частот $1104-988 \mathrm{~cm}^{-1}$ относится к группе колебаний $\mathrm{PO}_{4}$, присутствующей в составе апатита эмали зубов $[30,35,36]$. Полученное одномерное ИК-изображение (распределение $\mathrm{PO}_{4}$ группы на участке образца) позволило визуально обнаружить межфазную границу между эмалью и стоматологическим материалом (рис. $2 b$ ). Анализ полученной информации показывает, что в области стоматологического материала не содержится фосфатных групп. Вся граничащая с эмалью область, где наблюдается ненулевая интенсивность активных колебаний спектра в диапазоне 1104-988 $\mathrm{cm}^{-1}$, имеет размеры $\sim 14 \mu \mathrm{m}$ и показана на рис. $3 b$ пунктирной линией.

Весьма интересным на ИК-изображении распределения фосфатной группы (рис $3 b$ ) представляется участок, имеющий интенсивность поглощения группы колебаний $\mathrm{PO}_{4}$ от 1.5 до 6.5.
Это зона представляет собой биомиметический переходной слой, в состав которого в данном исследовании был включён синтезированный по разработанной нами методике КГАП. ИК-спектры этого материала изучались нами в работе [43]. Благодаря включению КГАП в биомиметический переходной слой на ИК-карте (рис. $3 b$ ) хорошо заметна межфазная граница между стоматологический материалом и эмалью, где резкая градация по цвету определяется интенсивностью моды колебаний группы $\mathrm{PO}_{4}$ гидроксиаптатита.

Необходимо отметить, что анализ ИК-изображения, отображающего распределение только фосфатной составляющей (рис. $3 b$ ), не является достаточным для исследования процессов интеграции стоматологического материала с эмалью зуба при использовании биомиметического буферного слоя. Во-первых, потому, что на этапе подготовки образов выполнялась как механическая, так и химическая подготовка зубной ткани для закрепления буферного слоя и материала (см. раздел Методика подготовки материалов). Кроме того в области $900-1100 \mathrm{~cm}^{-1}$ может происходить перекрытие ИК-полос поглощения фосфатных групп с неосновными колебаниями от стоматологического материала, что делает анализ межфазной границы неоднозначным. Поэтому для получения дополнительной информации об участке, содержащей межфазную границу, построено ИК-изображение, представленное на рис. $4 b$. Эта ИК-карта показывает распределение интенсивности полос поглощения (группы $\mathrm{CH}_{2}-\mathrm{CH}_{3}$ и амидной компоненты), соотносимых с молекулярными группами, характерными как для органической составляющей эмали, так и входящих в состав биомиметического буферного слоя (рис. $4 a)$.

Важно подчеркнуть, что полосу поглощения в области от 1524-1365 cm-1 можно было бы отнести к характеристическим колебаниям от карбонат-замещенного гидроксиапататита кальция В-типа [38]. Однако, как показали результаты из нашей работы [43], колебательные моды органической составляющей эмалевого матрикса имеют иной характеристический профиль и существенно большую интенсивность. Кроме того, полученный ИК-спектр эмали зубов в работе [43] полностью совпадает с экспериментальным ИК-спектром эмали в данной работе (рис. $4 a$ ). Это однозначно характеризует органическую составляющую эмали в ИК-спектре. Следует отметить, что построенное ИК-изображение по группе полос 1524-1365 cm-1 (cм. рис. $4 b$ ) позволяет совместно с оптическим изображением анали- 


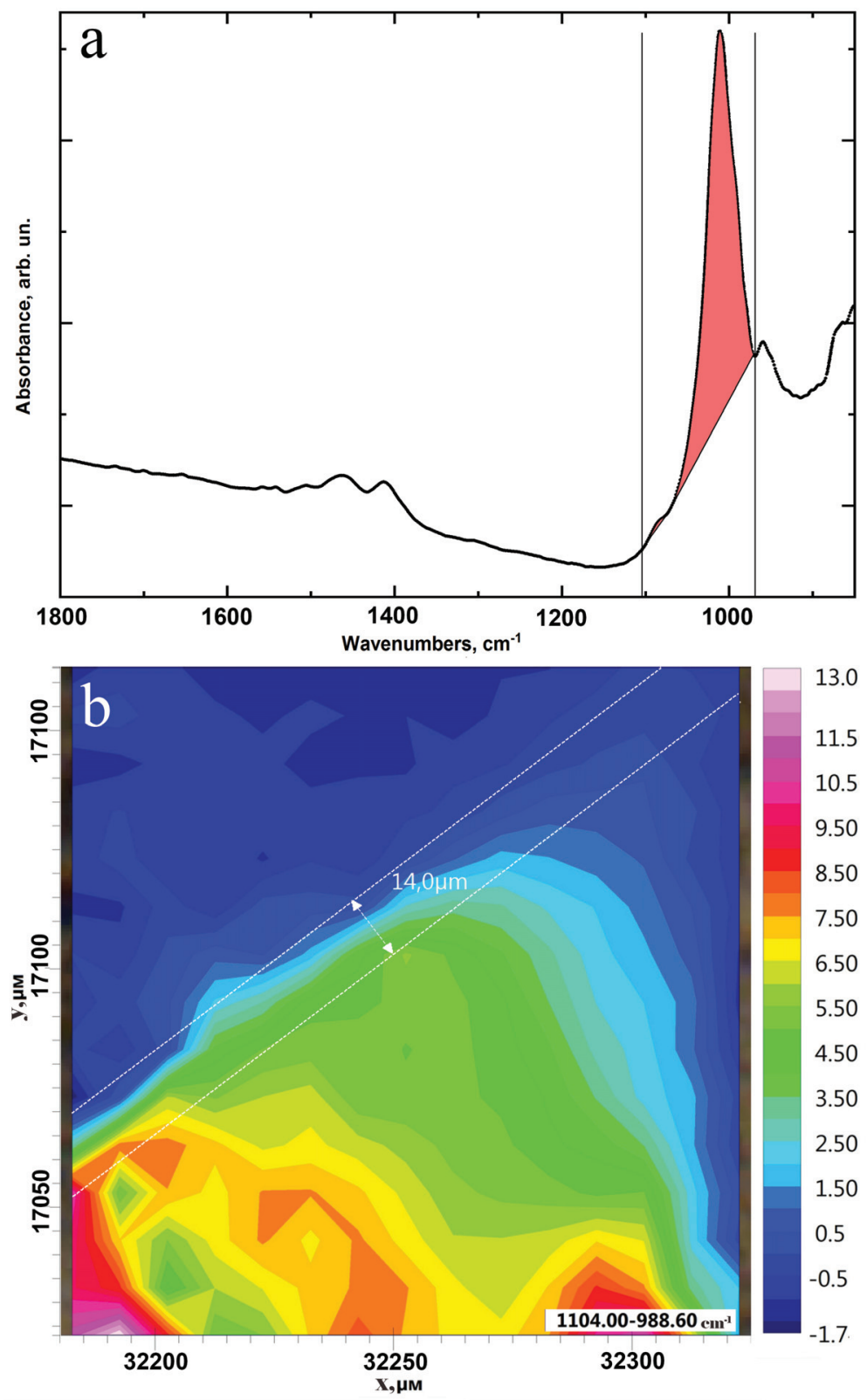

Рис. 3. ИК-спектр поглощения из области эмали образца, содержащий характерную фосфатную моду в области 1104-988 cm-1 , относимую к апатиту эмали (a) и характерное ИК-изображение, полученное на основе цветового кодирования интенсивности полосы спектра $1104-988 \mathrm{~cm}^{-1}(b)$

[Fig. 3. IR absorption spectrum from the enamel area of the sample, containing the characteristic phosphate mode in the $1104-988 \mathrm{~cm}^{-1}$ region, attributed to the enamel apatite (a) and the characteristic IR image obtained on the basis of color coding of the intensity of the absorption band $\left.1104-988 \mathrm{~cm}^{-1}(b)\right]$

зируемого участка образца (рис. $2 b)$ выделить область нативной эмали зуба.

Анализируя ИК-изображение рис. $4 b$ в приграничной области стоматологический материал/биомиметический композит/эмаль зуба хорошо видно, что существующая градация цветового кодирования интенсивности колебательных полос, относимых к органическому матриксу, аналогична той, которую можно наблюдать на ИК-карте распределения фосфатной составля- ющей (рис. 3b). Однако следует отметить более гомогенное распределение органической составляющей в буферном слое (рис. $4 b$ ) по сравнению с распределением фосфатных групп. Это подтверждает тот факт, что в составе созданного нами на этапе пробоподготовки биомиметического переходного слоя, доля гидроксиапатита меньше, чем доля органической компоненты.

К сожалению, выбранная нами для создания ИК-изображения (рис. $4 b$ ) область колебаний 


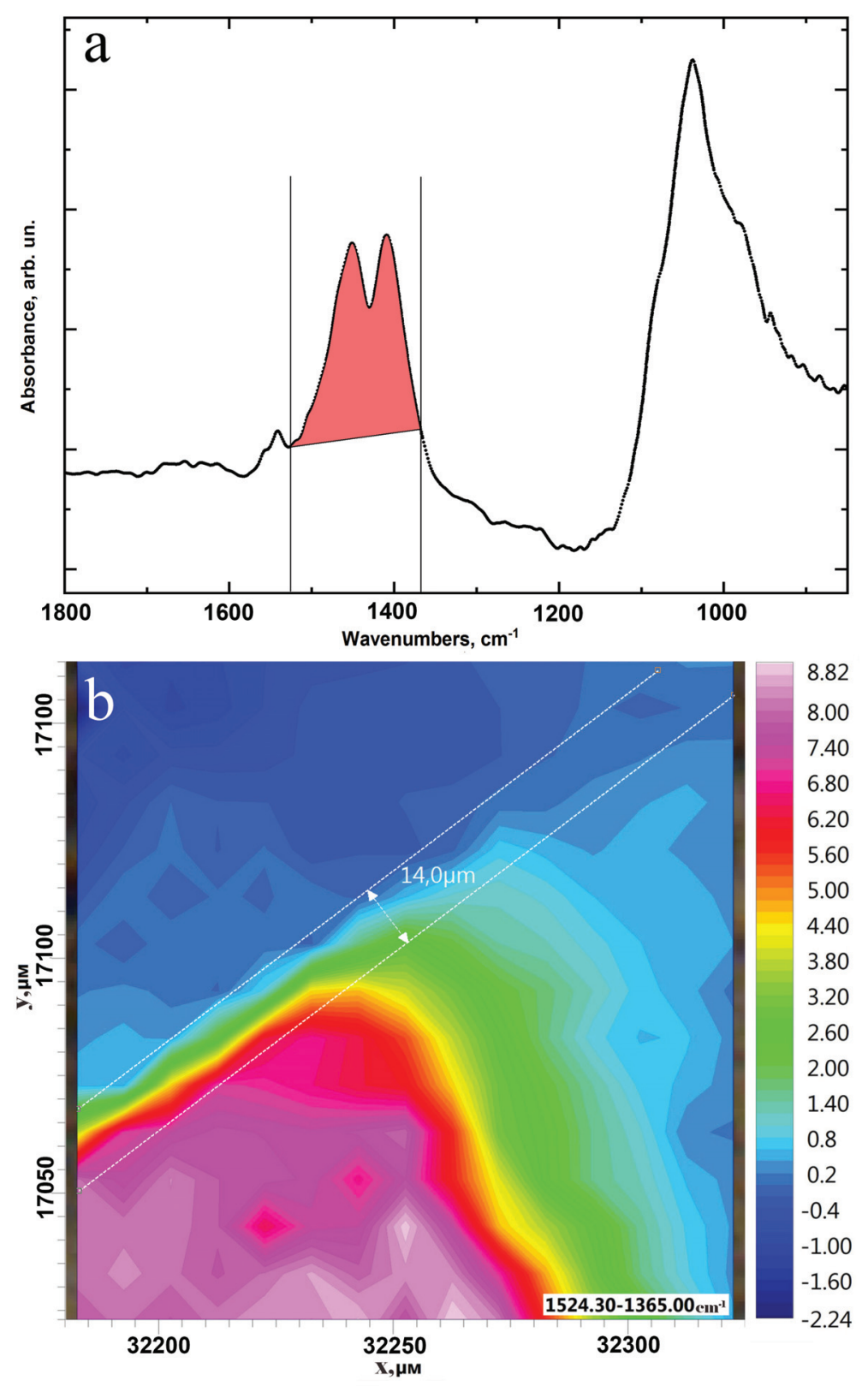

Рис. 4. ИК-спектр поглощения образца с колебательными модами органической составляющей в области 1524-1365 $\mathrm{cm}^{-1}($ a $)$ и характерное ИК-изображение, полученное на основе цветового кодирования интенсивности полосы спектра $1524-1365 \mathrm{~cm}^{-1}(b)$

[Fig. 4. The infrared absorption spectrum of the sample with the vibrational modes of the organic component in the region of $1524-1365 \mathrm{~cm}^{-1}(a)$ and the characteristic infrared image obtained on the basis of color coding of the intensity of the absorption band of $\left.1524-1365 \mathrm{~cm}^{-1}(b)\right]$

$1524-1365 \mathrm{~cm}^{-1}$ в ИК-спектре содержит целый ряд перекрывающихся полос, что, ровно, как и в случае ИК-карты распределения неорганической компоненты, не позволяет однозначно делать выводы о формировании границы интеграции между эмалью и стоматологическим светоотверждаемым цементом.

Для более полной оценки межфазной границы было проведено исследование ИК-спектров коммерческого компомерного рестав- рационного материала Dyract XP. Анализируя спектр, приведенный на рис. $5 a$, обращает на себя внимание тот факт, что он содержит широкую и высокоинтенсивную моду колебаний в области 1000-1100 cm $\mathrm{cm}^{-1}$. Эта колебательная полоса может принадлежать молекулярной группе силикатов алюминия или оксида кремния, используемых как наполнители светоотверждаемых цементов, и не связана с фосфатными компонентами биомиметического матери- 


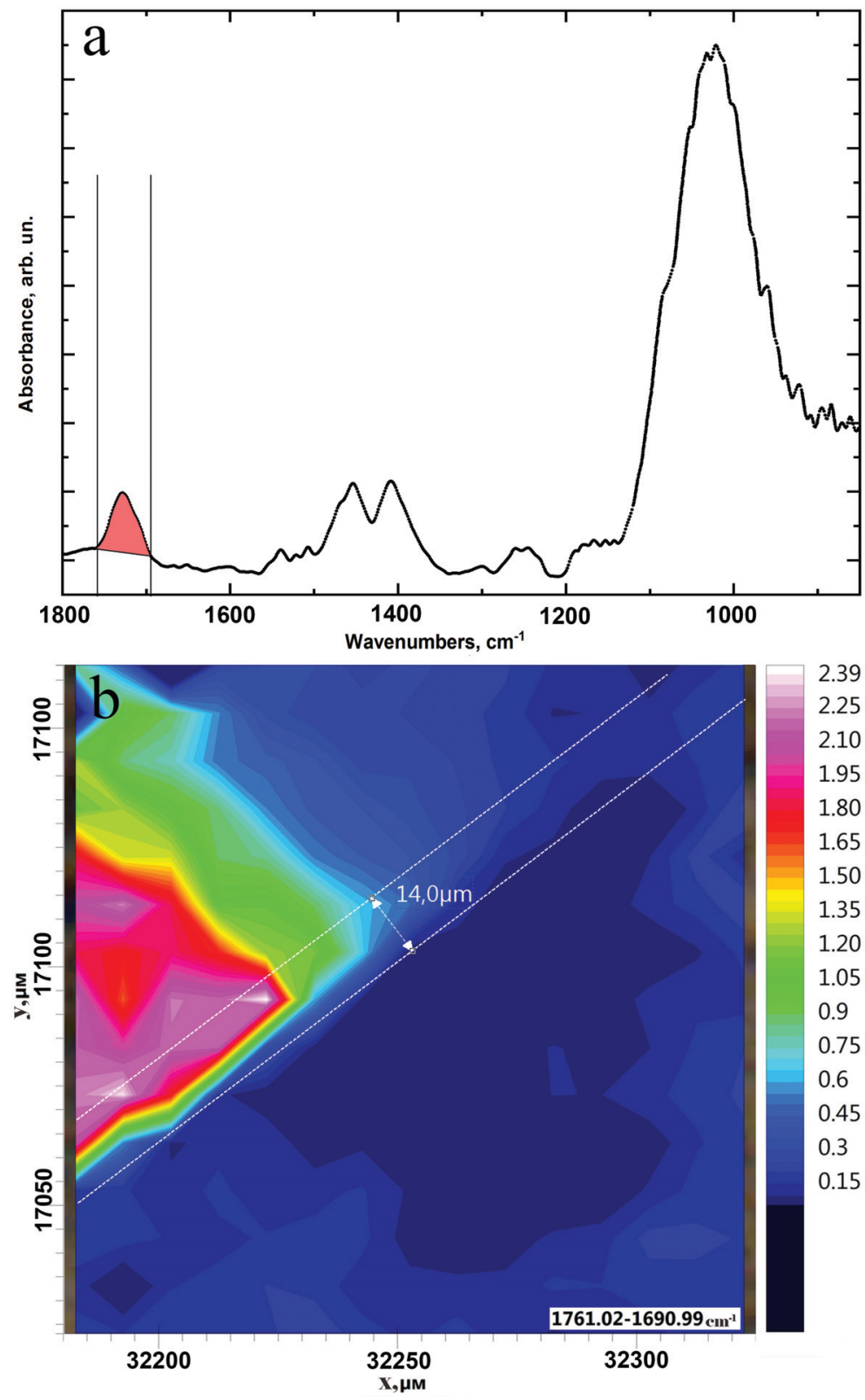

Рис. 5. ИК-спектр поглощения, с особенностью в области 1761-1690 $\mathrm{cm}^{-1}$ относимой к молекулярной группе эфира $\left(-\mathrm{COOCH}_{3}\right)$ материала Dyract XP (a) и характерное ИК-изображение, полученное на основе цветового кодирования интенсивности полосы спектра 1761-1690 $\mathrm{cm}^{-1}(b)$

[Fig. 5. Infrared absorption spectrum, with a feature in the area of $1761-1690 \mathrm{~cm}^{-1}$ that are refer to the ester $\left(-\mathrm{COOCH}_{3}\right)$ molecular group of relevant material Dyract XP $(a)$ and the characteristic infrared image ob-

tained on the basis of color coding of the intensity of the absorption band of $\left.1761-1690 \mathrm{~cm}^{-1}(b)\right]$

ала. В тоже время, группа колебаний в области $1200-1600 \mathrm{~cm}^{-1}$ присутствует в спектре, полученном из области стоматологического материала, в виду наличия в его составе синтетических добавок, используемых для фотополимеризации и связывания стоматологических цементов типа БИС-ГМА.

Однако в ИК-спектре из области стоматологического материала, можно заметить еще одну полосу поглощения, расположенную в области
$1725 \mathrm{~cm}^{-1}$ (рис. 5a). В работе [30] было показано, что эта полоса является характеристической особенностью ИК-спектров стоматологических цементов на основе БИС-ГМА и полметилметакрилата и принадлежит молекулярной группе эфира $\left(-\mathrm{COOCH}_{3}\right)$. Важно подчеркнуть, что это колебание не перекрывается с другими полосами, а, следовательно, делает одномерный анализ ИК-поглощения на основе этого параметра более достоверным, дающим информацию о про- 
странственном распределении стоматологического материала в анализируемой области.

Из рис. $5 b$ видно, что максимальное распределение интенсивности колебательной моды группы эфира (-COOCH$\left.{ }_{3}\right)$ совпадает с наблюдаемым на оптическом снимке расположением материала (рис. 2b). Особенное внимание привлекает область интеграции стоматологического материала с эмалью, где перепад интенсивности данной колебательной моды от максимального до минимального наблюдается в пространственном интервале $14 \mu \mathrm{m}$ и накладывается на зону, в которой в больше степени преобладает органическая составляющая эмали (рис. $4 b)$.

Необходимо подчеркнуть, что одновременный анализ нескольких ИК-карт, построенных на основе анализа выделенных, в том числе единичных полос, не всегда позволяет визуализировать изменения в гетерофазной границы между близкими по структуре материалами. Это связано с ограничениями одномерного подхода к выявлению спектральных изменений. Перечисленные проблемы могут быть решены с использованием многомерных методов кластеризации, позволяющих эффективно классифицировать большое количество компонентных спектров. Используя этот подход, нам удалось проанализировать особенности сложного интерфейса стоматологи- ческий материал/биомиметический композит/ эмаль зуба. Одновременный анализ, выполненный с учетом всех особенностей в спектральных областях 1760-1690 cm-1 и 1520-1360 cm-1, обнаруживает, что взаимодействие между стоматологическим материалом и эмалью, происходит посредством буферного слоя. Схематично на рис. 6 показаны результаты кластеризации с выделением области биомиметического композита.

В выделенной на рис. 6 пунктиром области схематично показано, что буферный переходной слой между эмалью и коммерческим материалом образуется за счёт связывания с частично деминерализованным эмалевым матриксом, что может указывать на возникновение органоминерального взаимодействия в анализируемой области. Исходя из имеющихся данных, можно предположить, что реальная величина буферного (интегрирующего) слоя составляет от 3 до $4 \mu \mathrm{m}$.

Полученные на основе анализа всех ИК-изображений данные (рис. 3-6) доподлинно свидетельствуют о химической дифференциации функциональных групп всех материалов в области границы биомиметическая система/естественная твердая ткань и подтверждают эффективность выбранного подхода для анализа интеграции стоматологических цементов и биомиметических композитов нового поколения.

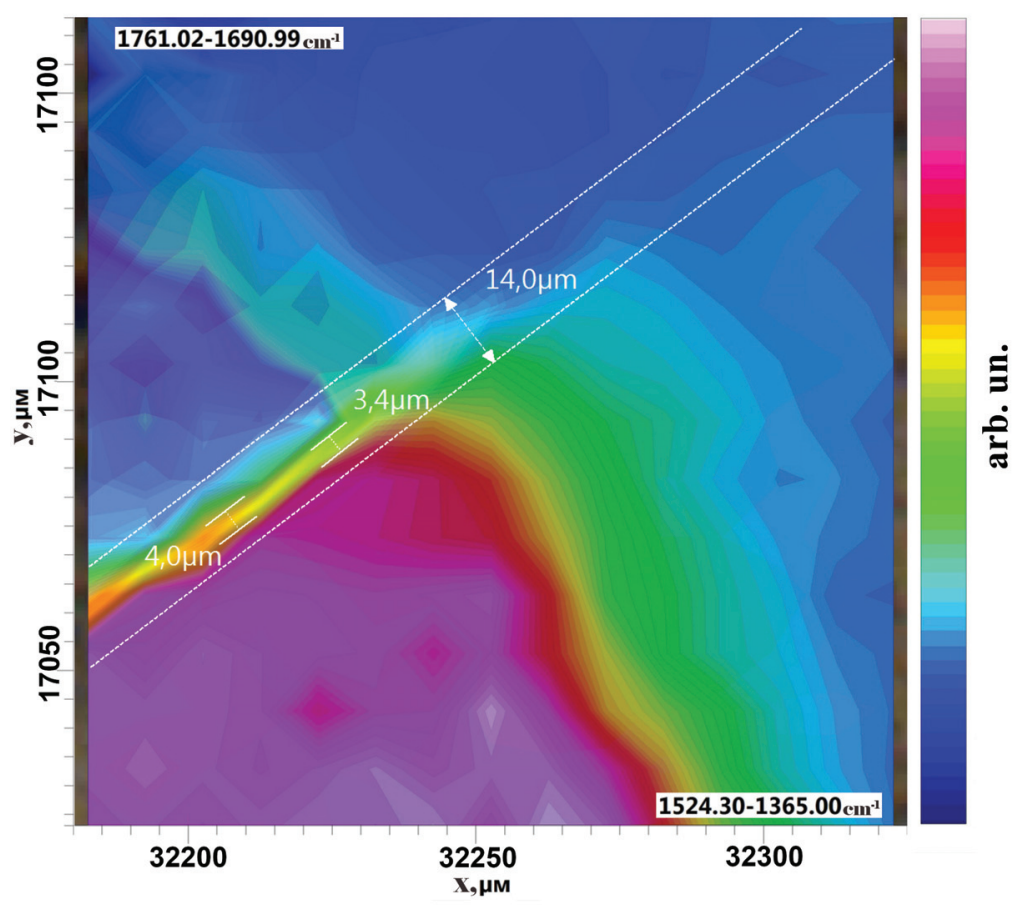

Рис. 6. ИК-изображение, полученное за счет использование метода крастеризации по особенностям в области 1760-1690 $\mathrm{cm}^{-1}$ и 1520-1360 $\mathrm{cm}^{-1}$ ]

[Fig. 6. Infrared image obtained by using the method of crushing by features in the area of $1760-1690 \mathrm{~cm}^{-1}$ and $1520-1360 \mathrm{~cm}^{-1}$ ] 


\section{ЗАКЛЮЧЕНИЕ И ВЫВОДЫ}

В данной работе продемонстрирована возможность применения молекулярной многомерной ИК-визуализации для анализа интеграции нового поколения биомиметических материалов, воспроизводящих минералорганический комплекс эмали с нативными твердыми тканями зуба человека.

С применением ИК-картирования интенсивности конкретной функциональной молекулярной группы с использованием синхротронного излучения были найдены и визуализированы различия между здоровой тканью, стоматологическим материалом и биомиметическим переходным слоем в межфазных областях, а также определены расположение и концентрация функциональных групп, отвечающих процессам интеграции биомиметического композита и нативной твёрдой ткани зуба человека

Показано, что разработанная нами биомиметическая система, на основе нанокристаллического карбонат-замещенного гидроксиапатита, полученного из биогенного источника кальция и комплекса основных полярных аминокислот, соответствующих органоминеральному комплексу зубов человека, способна образовывать функциональную связь с твердой тканью зуба человека.

Полученные нами микроспектроскопические данные достоверно подтверждают химическую дифференциацию материалов и наличие органоминерального взаимодействия на границе биомиметическая система/естественная твердая ткань.

\section{ИСТОЧНИК ФИНАНСИРОВАНИЯ}

Исследование выполнено при поддержке РФФИ (грант № 18-29-11008 мк).

Исследование в части синтеза нанокристаллического карбонатзамещенного гидроксиапатита кальция для создания биомиметических композитов было выполнено при поддержке гранта Президента Российской Федерации № MK-419.2019.2.

\section{КОНФЛИКТ ИНТЕРЕСОВ}

Авторы декларируют отсутствие явных и потенциальных конфликтов интересов, связанных с публикацией настоящей статьи

\section{СПИСОК ЛИТЕРАТУРЫ}

1. Rohr N., Fischer J. Tooth surface treatment strategies for adhesive cementation // The Journal of Advanced Prosthodontics, 2017, v. 9(2), pp. 85-92. DOI: 10.4047/jap.2017.9.2.85
2. Pereira C. N. de B., Daleprane B., Miranda G. L. P. de, Magalhães C. S. de, Moreira A. N. Ultramorphology of pre-treated adhesive interfaces between self-adhesive resin cement and tooth structures // Revista de Odontologia da UNESP, 2017, v. 46(5), pp. 249-254. DOI: $10.1590 / 1807-2577.04917$

3. Temel U. B., Van Ende A., Van Meerbeek B., Ermis R. B. Bond strength and cement-tooth interfacial characterization of self-adhesive composite cements // American Journal of Dentistry, 2017, v. 30(4), pp. 205211.

4. Watson T. F., Atmeh A. R., Sajini S., Cook R. J., Festy F. Present and future of glass-ionomers and calcium-silicate cements as bioactive materials in dentistry: Biophotonics-based interfacial analyses in health and disease // Dental Materials, 2014, v. 30(1), pp. 50-61. DOI: 10.1016/j.dental.2013.08.202

5. Pontes D. G., Araujo C. T. P., Prieto L. T., de Oliveira D. C. R. S., Coppini E. K., Dias C. T. S., Paulillo L. A. M. S. Nanoleakage of fiber posts luted with different adhesive strategies and the effect of chlorhexidine on the interface of dentin and self-adhesive cements // General Dentistry, 2015, v. 63(3), pp. 31-37. PMID: 25945761

6. Teaford M. F., Smith M. M., Ferguson M. W. J. Development, Function and Evolution of Teeth. Cambridge University Press, 2007, 328 p.

7. Dorozhkin S. V. Hydroxyapatite and Other Calcium Orthophosphates: Bioceramics, Coatings and Dental Applications [Hardcover]. Nova Science Publishers, Inc New York, 2017, 462 p. URL: https://istina.msu. ru/publications/book/58538935/

8. Uskoković V. Biomineralization and biomimicry of tooth enamel. Non-Metallic Biomaterials for Tooth Repair and Replacement. Elsevier, 2013, pp. 20-44. URL: http://linkinghub.elsevier.com/retrieve/pii/ B9780857092441500021

9. Niu L., Zhang W., Pashley D. H., Breschi L., Mao J., Chen J., Tay F. R. Biomimetic remineralization of dentin // Dental Materials, 2014, v. 30(1), pp. 77-96. DOI: 10.1016/j.dental.2013.07.013

10. Cao C., Mei M., Li Q., Lo E., Chu C. Methods for Biomimetic Mineralisation of Human Enamel: A Systematic Review // Materials, 2015, v. 8(6), pp. 28732886. DOI: $10.3390 / \mathrm{ma} 8062873$

11. Chen L., Yuan H., Tang B., Liang K., Li J. Biomimetic remineralization of human enamel in the presence of polyamidoamine dendrimers in vitro // Caries Research, 2015, v. 49(3), pp. 282-290. DOI: 10.1159/000375376

12. Seredin P. V., Goloshchapov D. L., Gushchin M. S., Ippolitov Y. A., Prutskij T. The importance of the biomimetic composites components for recreating the optical properties and molecular composition of intact dental tissues. // Journal of Physics: Conference Series, 2017, v. 917(4), pp.042019. DOI: 10.1088/17426596/917/4/042019 
13. Xia Z. Biomimetic Principles and Design of Advanced Engineering Materials. John Wiley \& Sons, 2016, $321 \mathrm{p}$.

14. Dorozhkin S. V. Self-Setting Calcium Orthophosphate Formulations: Cements, Concretes, Pastes and Putties // International Journal of Materials and Chemistry, 2012, v. 1(1), pp. 1-48. DOI: 10.5923/j. ijmc.20110101.01

15. Li H., Gong M., Yang A., Ma J., Li X., Yan Y. Degradable biocomposite of nano calcium-deficient hydroxyapatite-multi(amino acid) copolymer // International Journal of Nanomedicine, 2012, v. 7, pp. 12871295. DOI: $10.2147 /$ IJN.S28978

16. Ruan Q., Zhang Y., Yang X., Nutt S., MoradianOldak J. An amelogenin-chitosan matrix promotes assembly of an enamel-like layer with a dense interface // Acta Biomaterialia, 2013, v. 9(7), pp. 7289-7297. DOI: 10.1016/j.actbio.2013.04.004

17. Yao Y., Shao H., Zhang Q. Development and Characterization of a Novel Amorphous Calcium Phosphate/Multi (Amino Acid) Copolymer Composite for Bone Repair // Journal of Biomaterials and Tissue Engineering, 2015, v. 5(5), pp. 387-390. DOI: 10.1166/ jbt.2015.1321

18. Melo M. A. S., Weir M. D., Rodrigues L. K. A., $\mathrm{Xu}$ H. H. K. Novel calcium phosphate nanocomposite with caries-inhibition in a human in situ model // Dental Materials, 2013, v. 29(2), pp. 231-240. DOI: 10.1016/j.dental.2012.10.010

19. Wu X.-T., Mei M., Li Q.-L., Cao C., Chen J.-L., Xia R., Zhang Z.-H., Chu C. A Direct Electric FieldAided Biomimetic Mineralization System for Inducing the Remineralization of Dentin Collagen Matrix // Materials, 2015, v. 8(12), pp. 7889-7899. DOI: 10.3390/ ma8115433

20. Barghamadi H., Atai M., Imani M., Esfandeh M. Effects of nanoparticle size and content on mechanical properties of dental nanocomposites: experimental versus modeling // Iranian Polymer Journal, 2015, v. 24. (10), pp. 837-848. DOI: 10.1007/s13726-015-0369-5

21. Wang H., Xiao Z., Yang J., Lu D., Kishen A., Li Y., Chen Z., Que K., Zhang Q., Deng X., Yang X., Cai Q., Chen N., Cong C., Guan B., Li T., Zhang X. Oriented and Ordered Biomimetic Remineralization of the Surface of Demineralized Dental Enamel Using HAP@ ACP Nanoparticles Guided by Glycine // Scientific Reports, 2017, v. 7(1), pp. 1-13. DOI: 10.1038/srep40701

22. Wu X., Zhao X., Li Y., Yang T., Yan X., Wang K. In situ synthesis carbonated hydroxyapatite layers on enamel slices with acidic amino acids by a novel twostep method // Materials Science \& Engineering. C, Materials for Biological Applications, 2015, v. 54, pp. 150-157. DOI: 10.1016/j.msec.2015.05.006

23. Aljabo A., Abou Neel E. A., Knowles J. C., Young A. M. Development of dental composites with reactive fillers that promote precipitation of antibacterial-hydroxyapatite layers // Materials Science and
Engineering: C, 2016,v. 60,pp. 285-292.DOI: 10.1016/ j.msec.2015.11.047

24. Wang P., Liu P., Peng H., Luo X., Yuan H., Zhang J., Yan Y. Biocompatibility evaluation of dicalcium phosphate/calcium sulfate/poly (amino acid) composite for orthopedic tissue engineering in vitro and in vivo // Journal of Biomaterials Science. Polymer Edition, 2016, v. 27(11), pp. 1170-1186. DOI: 10.1080 /09205063.2016.1184123

25. Lübke A., Enax J., Wey K., Fabritius H.-O., Raabe D., Epple M. Composites of fluoroapatite and methylmethacrylate-based polymers (PMMA) for biomimetic tooth replacement // Bioinspiration \& Biomimetics, 2016, v. 11(3), pp. 035001. DOI: 10.1088/1748-3190/11/3/035001

26. Sa Y., Gao Y., Wang M., Wang T., Feng X., Wang Z., Wang Y., Jiang T. Bioactive calcium phosphate cement with excellent injectability, mineralization capacity and drug-delivery properties for dental biomimetic reconstruction and minimum intervention therapy. RSC Advances, 2016, v. 6(33), pp. 27349-27359. DOI: 10.1039/C6RA02488B

27. Adachi T., Pezzotti G., Yamamoto T., Ichioka H., Boffelli M., Zhu W., Kanamura N. Vibrational algorithms for quantitative crystallographic analyses of hydroxyapatite-based biomaterials: II, application to decayed human teeth // Analytical and Bioanalytical Chemistry, 2015, v. 407(12), pp. 3343-3356. DOI: 10.1007/s00216-015-8539-z

28. Mitić Ž., Stolić A., Stojanović S., Najman S., Ignjatović N., Nikolić G., Trajanović M. Instrumental methods and techniques for structural and physicochemical characterization of biomaterials and bone tissue: A review // Materials Science and Engineering: C, 2017, v. 79, pp. 930-949. DOI: 10.1016/j. msec.2017.05.127

29. Optical spectroscopy and computational methods in biology and medicine / Ed. by Barańska M., Dordrecht: Springer, 2014, 540 p. URL: http://link.springer. com/10.1007/978-94-007-7832-0

30. Hędzelek W., Marcinkowska A., Domka L., Wachowiak R. Infrared Spectroscopic Identification of Chosen Dental Materials and Natural Teeth // Acta Physica Polonica A, 2008, v. 114(2), pp. 471-484. DOI: 10.12693/APhysPolA.114.471

31. Vongsvivut J., Perez-Guaita D., Wood B. R., Heraud P., Khambatta K., Hartnell D., Hackett M. J., Tobin M. J. Synchrotron macro ATR-FTIR microspectroscopy for high-resolution chemical mapping of single cells // The Analyst, 2019, v. 144(10), pp. 32263238. DOI: 10.1039/c8an01543k

32. Seredin P., Goloshchapov D., Ippolitov Y., Vongsvivut P. Pathology-specific molecular profiles of saliva in patients with multiple dental caries-potential application for predictive, preventive and personalised medical services // EPMA Journal, 2018, v. 9(2), pp. 195-203. DOI: 10.1007/s13167-018-0135-9 
33. Dusevich V., Xu C., Wang Y., Walker M. P., Gorski J. P. Identification of a protein-containing enamel matrix layer which bridges with the dentine-enamel junction of adult human teeth // Archives of Oral Biology, 2012, v. 57(12), pp. 1585-1594. DOI: 10.1016/j. archoralbio.2012.04.014

34. Seredin P. V., Kashkarov V. M., Lukin A. N., Goloshchapov D. L., Ippolitov Y. A. Research Hydroxyapatite Crystals and Organic Components of Hard Tooth Tissues Affected by Dental Caries Using Ftir-Microspectroscopy and Xrd-Microdiffraction // Condensed Matter and Interphases, 2013, v. 15(3), c. 224-231.URL: http:// www.kcmf.vsu.ru/resources/t_15_3_2013_002.pdf

35. Fattibene P., Carosi A., Coste V.D., Sacchetti A., Nucara A., Postorino P., Dore P. A comparative EPR, infrared and Raman study of natural and deproteinated tooth enamel and dentin // Physics in Medicine and Biology, 2005, v. 50(6), pp. 1095.DOI: 10.1088/00319155/50/6/004

36. Seredin P., Goloshchapov D., Kashkarov V., Ippolitov Y., Bambery K. The investigations of changes in mineral-organic and carbon-phosphate ratios in the mixed saliva by synchrotron infrared spectroscopy // Results in Physics, 2016, v. 6, pp. 315-321. DOI: 10.1016/j.rinp.2016.06.005

37. Goloshchapov D. L., Kashkarov V. M., Rumyantseva N. A., Seredin P. V., Lenshin A. S., Agapov B. L., Domashevskaya E. P. Synthesis of nanocrystalline hydroxyapatite by precipitation using hen's eggshell // Ceramics International, 2013, v. 39(4), pp. 4539-4549. DOI: 10.1016/j.ceramint.2012.11.050
38. Goloshchapov D. L., Lenshin A. S., Savchenko D. V., Seredin P.V. Importance of defect nanocrystalline calcium hydroxyapatite characteristics for developing the dental biomimetic composites // Results in Physics, 2019, v. 13, pp. 102158. DOI: 10.1016/j. rinp.2019.102158

39. Nanci A. Ten Cate's Oral Histology: Development, Structure, and Function. 8th ed., Elsevier Health Sciences, 2013, $400 \mathrm{p}$.

40. Ипполитов Ю. А. Возможность повышения биологической тропности светоотверждаемой бондинговой системы для адгезии твердых тканей зуба к пломбировочному материалу // Волгоградский научно-медицинский журнал, 2010, т. 4 (28), c. 31-34.URL: https://www.volgmed.ru/uploads/journals/articles/1293119124-bulletin-2010-4-815.pdf

41. Seredin P., Goloshchapov D., Prutskij T., Ippolitov Y. Phase Transformations in a Human Tooth Tissue at the Initial Stage of Caries // PLOS ONE, 2015, v. 10(4), pp. 1-11. DOI: 10.1371/journal.pone.0124008

42. Середин П. В., Голощапов Д. Л., Prutskij Т., Ипполитов Ю. А. Единовременный анализ микрообластей кариозного дентина методами лазерноиндуцированной флуоресценции и рамановской спектромикроскопии // Оптика и спектроскопия, 2018, т. 125(11), c. 708. DOIЖ 10.21883/ OS.2018.11.46847.173-18

43. Seredin P. V., Goloshchapov D. L., Prutskij T., Ippolitov Yu. A. Fabrication and characterisation of composites materials similar optically and in composition to native dental tissues // Results in Physics, 2017, v. 7, pp. 1086-1094. DOI: 10.1016/j.rinp.2017.02.025

UDC 53.05

DOI: https://doi.org/10.17308/kcmf.2019.21/764

Received 10.05.2019

Accepted 15.05.2019

\title{
APPLICATION OF SYNCHROTRONIC IR-MICROSPECTROSCOPY FOR ANALYSIS OF INTEGRATION OF BIOMIMETIC COMPOSITES WITH NATIVE DENTAL TISSUES
}

\section{(c) 2019 P. V. Seredin $\bowtie 1$, D. L. Goloshchapov ${ }^{1}$, V. M. Kashkarov ${ }^{1}$, K. A. Nikitkov ${ }^{1}$, V. N. Bartenev ${ }^{1}$, Y. A. Ippolitov ${ }^{2}$, Jitraporn (Pimm) Vongsvivut ${ }^{3}$}

\author{
${ }^{1}$ Voronezh State University \\ 1, Universitetskaya pl., 394018 Voronezh, Russian Federation \\ ${ }^{2}$ Voronezh State Medical University named after N.N. Burdenko \\ 10, Studencheskaja str., 394036 Voronezh, Russian Federation \\ ${ }^{3}$ Australian Synchrotron (Synchrotron Light Source Australia Pty LTD) \\ 800 Blackburn Rd Clayton, VIC 3168, Australia
}

\begin{abstract}
Purpose. The purpose of our work was the study of the features in molecular composition of the interface between dental product - biomimetic composite - hard dental tissue with the use
\end{abstract}

\ Seredin Pavel V., e-mail: paul@phys.ru 
of multidimensional visualization of IR-microspectroscopy data obtained using synchrotron radiation as well as the determination of the advantages of this method for the analysis of organic-mineral interaction between synthetic biomimetic material with hard dental tissues of a human.

Methods and methodology. Technique for the preparation of the samples in order to study the interaction between dental product - biomimetic composite - hard dental tissue involved the following stages: 1 - development of biocomposite substance with the use of nanocrystalline carbonate-substituted calcium hydroxyapatite and a mixture of the main amino acids, that were found in the composition of the native dental matrix; 2 - recovery of the prepared carious areas of enamel with the use of our proposed biomimetic buffer system; 3 - obtaining of plane-parallel segments of the human teeth comprising the regions of the interface with the use of low-invasive methods for separation and polishing.

Investigations of molecular composition in the slices of human teeth were performed by mapping technique of IR-microspectroscopy data obtained by applying attenuated total reflection technique (ATR-spectroscopy). The study was performed with the use of equipment of Infrared Microspectroscopy (IRM) beamline (Australian synchrotron, Melbourne, Australia).

Results. Applying IR-mapping for the distribution of a certain functional molecular group obtained with the use of synchrotron radiation the difference between the sound dental tissue, dental product and biomimetic transition layer in the interphase areas were found and visualized. In addition, the arrangement and concentration of the functional groups were determined, corresponding to the processes of integration between the biomimetic composite and the native hard dental tissue of a man.

Biomimetic system on the basis of nanocrystalline carbonate-substituted calcium hydroxyapatite obtained from biogenic source of calcium and a complex of the main polar amino acids corresponding to the organic-mineral complex of the human teeth that was elaborated in our laboratory was shown to form a functional linkage with the hard dental tissue of a man.

Conclusion. Thus, our microspectroscopy data certainly confirm the chemical differentiation of materials and the presence of organic-mineral interaction at the boundary of biomimetic system/native hard dental tissue.

Keywords: biomimetic materials, native human tooth hard tissue, IR microspectroscopy, synchrotron radiation.

\section{FUNDINGS}

The study was supported by the Russian Foundation for Basic Research (Grant No. 18-29$11008 \mathrm{mk})$.

The study on the synthesis of nanocrystalline carbonate-substituted calcium hydroxyapatite for the creation of biomimetic composites was carried out with the support of the grant of the President of the Russian Federation No. MK-419.2019.2.

\section{CONFLICT OF INTEREST}

The authors declare the absence of obvious and potential conflicts of interest related to the publication of this article.

\section{ETHICS APPROVAL AND CONSENT TO PARTICIPATE}

All patients whose data were used within the created survey had signed institutional consent for the participation research. All persons who participated in the survey signed written consent. Voronezh State University Ethics Committee approved this study (approval number 001.018-2017). The study was carried out in accordance with the approved guidelines.

\section{REFERENCES}

1. Rohr N., Fischer J. Tooth surface treatment strategies for adhesive cementation. The Journal of Advanced Prosthodontics, 2017, v. 9(2), pp. 85-92. DOI: 10.4047/jap.2017.9.2.85

2. Pereira C. N. de B., Daleprane B., Miranda G. L. P. de, Magalhães C. S. de, Moreira A. N. Ultramorphology of pre-treated adhesive interfaces between self-adhesive resin cement and tooth structures. Revista de Odontologia da UNESP, 2017, v. 46(5), pp. 249-254. DOI: 10.1590/1807-2577.04917

3. Temel U. B., Van Ende A., Van Meerbeek B., Ermis R. B. Bond strength and cement-tooth interfacial characterization of self-adhesive composite cements. American Journal of Dentistry, 2017, v. 30(4), pp. 205211.

4. Watson T. F., Atmeh A. R., Sajini S., Cook R. J., Festy F. Present and future of glass-ionomers and calcium-silicate cements as bioactive materials in dentistry: Biophotonics-based interfacial analyses in health and disease. Dental Materials, 2014, v. 30(1), pp. 50-61. DOI: 10.1016/j.dental.2013.08.202

5. Pontes D. G., Araujo C. T. P., Prieto L. T., de Oliveira D. C. R. S., Coppini E. K., Dias C. T. S., Paulillo L. A. M. S. Nanoleakage of fiber posts luted with 
different adhesive strategies and the effect of chlorhexidine on the interface of dentin and self-adhesive cements. General Dentistry, 2015, v. 63(3), pp. 31-37. PMID: 25945761

6. Teaford M. F., Smith M. M., Ferguson M. W. J. Development, Function and Evolution of Teeth. Cambridge University Press, 2007, 328 p.

7. Dorozhkin S. V. Hydroxyapatite and Other Calcium Orthophosphates: Bioceramics, Coatings and Dental Applications [Hardcover]. Nova Science Publishers, Inc New York, 2017, 462 p. URL: https://istina. msu.ru/publications/book/58538935/

8. Uskoković V. Biomineralization and biomimicry of tooth enamel. Non-Metallic Biomaterials for Tooth Repair and Replacement. Elsevier, 2013, pp. 20-44. URL: http://linkinghub.elsevier.com/retrieve/pii/ B9780857092441500021

9. Niu L., Zhang W., Pashley D. H., Breschi L., Mao J., Chen J., Tay F. R. Biomimetic remineralization of dentin. Dental Materials, 2014, v. 30(1), pp. 77-96. DOI: 10.1016/j.dental.2013.07.013

10. Cao C., Mei M., Li Q., Lo E., Chu C. Methods for Biomimetic Mineralisation of Human Enamel: A Systematic Review. Materials, 2015, v. 8(6), pp. 2873-2886. DOI: $10.3390 / \mathrm{ma} 8062873$

11. Chen L., Yuan H., Tang B., Liang K., Li J. Biomimetic remineralization of human enamel in the presence of polyamidoamine dendrimers in vitro. $\mathrm{Ca}$ ries Research, 2015, v. 49(3), pp. 282-290. DOI: 10.1159/000375376

12. Seredin P. V., Goloshchapov D. L., Gushchin M. S., Ippolitov Y. A., Prutskij T. The importance of the biomimetic composites components for recreating the optical properties and molecular composition of intact dental tissues.. Journal of Physics: Conference Series, 2017, v. 917(4), pp.042019. DOI: 10.1088/17426596/917/4/042019

13. Xia Z. Biomimetic Principles and Design of Advanced Engineering Materials. John Wiley \& Sons, 2016, $321 \mathrm{p}$.

14. Dorozhkin S. V. Self-Setting Calcium Orthophosphate Formulations: Cements, Concretes, Pastes and Putties. International Journal of Materials and Chemistry, 2012, v. 1(1), pp. 1-48. DOI: 10.5923/j. ijmc.20110101.01

15. Li H., Gong M., Yang A., Ma J., Li X., Yan Y. Degradable biocomposite of nano calcium-deficient hydroxyapatite-multi(amino acid) copolymer. International Journal of Nanomedicine, 2012, v. 7, pp. 12871295. DOI: $10.2147 /$ IJN.S28978

16. Ruan Q., Zhang Y., Yang X., Nutt S., MoradianOldak J. An amelogenin-chitosan matrix promotes assembly of an enamel-like layer with a dense interface // Acta Biomaterialia, 2013, v. 9(7), pp. 7289-7297. DOI: 10.1016/j.actbio.2013.04.004

17. Yao Y., Shao H., Zhang Q. Development and Characterization of a Novel Amorphous Calcium Phos-
phate/Multi (Amino Acid) Copolymer Composite for Bone Repair. Journal of Biomaterials and Tissue Engineering, 2015, v. 5(5), pp. 387-390. DOI: 10.1166/ jbt.2015.1321

18. Melo M. A. S., Weir M. D., Rodrigues L. K. A., $\mathrm{Xu}$ H. H. K. Novel calcium phosphate nanocomposite with caries-inhibition in a human in situ model. Dental Materials, 2013, v. 29(2), pp. 231-240. DOI: 10.1016/ j.dental.2012.10.010

19. Wu X.-T., Mei M., Li Q.-L., Cao C., Chen J.-L., Xia R., Zhang Z.-H., Chu C. A Direct Electric FieldAided Biomimetic Mineralization System for Inducing the Remineralization of Dentin Collagen Matrix. $\mathrm{Ma}-$ terials, 2015, v. 8(12), pp. 7889-7899. DOI: 10.3390/ ma8115433

20. Barghamadi H., Atai M., Imani M., Esfandeh M. Effects of nanoparticle size and content on mechanical properties of dental nanocomposites: experimental versus modeling. Iranian Polymer Journal, 2015, v. 24. (10), pp. 837-848. DOI: 10.1007/s13726-0150369-5

21. Wang H., Xiao Z., Yang J., Lu D., Kishen A., Li Y., Chen Z., Que K., Zhang Q., Deng X., Yang X., Cai Q., Chen N., Cong C., Guan B., Li T., Zhang X. Oriented and Ordered Biomimetic Remineralization of the Surface of Demineralized Dental Enamel Using HAP@ ACP Nanoparticles Guided by Glycine. Scientific Reports, 2017, v. 7(1), pp. 1-13. DOI: 10.1038/srep40701

22. Wu X., Zhao X., Li Y., Yang T., Yan X., Wang K. In situ synthesis carbonated hydroxyapatite layers on enamel slices with acidic amino acids by a novel twostep method. Materials Science \& Engineering. C, Materials for Biological Applications, 2015, v. 54, pp. 150157. DOI: 10.1016/j.msec.2015.05.006

23. Aljabo A., Abou Neel E. A., Knowles J. C., Young A. M. Development of dental composites with reactive fillers that promote precipitation of antibacterial-hydroxyapatite layers. Materials Science and Engineering: C, 2016, v. 60, pp. 285-292.DOI: 10.1016/ j.msec.2015.11.047

24. Wang P., Liu P., Peng H., Luo X., Yuan H., Zhang J., Yan Y. Biocompatibility evaluation of dicalcium phosphate/calcium sulfate/poly (amino acid) composite for orthopedic tissue engineering in vitro and in vivo. Journal of Biomaterials Science. Polymer Edition, 2016, v. 27(11), pp. 1170-1186. DOI: 10.1080 /09205063.2016.1184123

25. Lübke A., Enax J., Wey K., Fabritius H.-O., Raabe D., Epple M. Composites of fluoroapatite and methylmethacrylate-based polymers (PMMA) for biomimetic tooth replacement. Bioinspiration \& Biomimetics, 2016, v. 11(3), pp.035001.DOI: 10.1088/17483190/11/3/035001

26. Sa Y., Gao Y., Wang M., Wang T., Feng X., Wang Z., Wang Y., Jiang T. Bioactive calcium phosphate cement with excellent injectability, mineralization capacity and drug-delivery properties for dental bio- 
mimetic reconstruction and minimum intervention therapy. RSCAdvances, 2016, v. 6(33), pp. 27349-27359. DOI: 10.1039/C6RA02488B

27. Adachi T., Pezzotti G., Yamamoto T., Ichioka H., Boffelli M., Zhu W., Kanamura N. Vibrational algorithms for quantitative crystallographic analyses of hydroxyapatite-based biomaterials: II, application to decayed human teeth. Analytical and Bioanalytical Chemistry, 2015, v. 407(12), pp. 3343-3356. DOI: 10.1007/s00216-015-8539-z

28. Mitić Ž., Stolić A., Stojanović S., Najman S., Ignjatović N., Nikolić G., Trajanović M. Instrumental methods and techniques for structural and physicochemical characterization of biomaterials and bone tissue: A review. Materials Science and Engineering: $C$, 2017, v. 79, pp. 930-949. DOI: 10.1016/j. msec.2017.05.127

29. Optical spectroscopy and computational methods in biology and medicine / Ed. by Barańska M., Dordrecht: Springer, 2014, 540 p. URL: http://link.springer. com/10.1007/978-94-007-7832-0

30. Hędzelek W., Marcinkowska A., Domka L., Wachowiak R. Infrared Spectroscopic Identification of Chosen Dental Materials and Natural Teeth. Acta Physica Polonica A, 2008, v. 114(2), pp. 471-484. DOI: 10.12693/APhysPolA.114.471

31. Vongsvivut J., Perez-Guaita D., Wood B. R., Heraud P., Khambatta K., Hartnell D., Hackett M. J., Tobin M. J. Synchrotron macro ATR-FTIR microspectroscopy for high-resolution chemical mapping of single cells. The Analyst, 2019, v. 144(10), pp. 32263238. D OI: 10.1039/c8an01543k

32. Seredin P., Goloshchapov D., Ippolitov Y., Vongsvivut P. Pathology-specific molecular profiles of saliva in patients with multiple dental caries-potential application for predictive, preventive and personalised medical services. EPMA Journal, 2018, v. 9(2), pp. 195-203. DOI: 10.1007/s13167-018-0135-9

33. Dusevich V., Xu C., Wang Y., Walker M. P., Gorski J. P. Identification of a protein-containing enamel matrix layer which bridges with the dentine-enamel junction of adult human teeth. Archives of Oral Biology, 2012, v. 57(12), pp. 1585-1594. DOI: $10.1016 / \mathrm{j}$. archoralbio.2012.04.014

34. Seredin P. V., Kashkarov V. M., Lukin A. N., Goloshchapov D. L., Ippolitov Y. A. Research Hydroxyapatite Crystals and Organic Components of Hard Tooth Tissues Affected by Dental Caries Using FtirMicrospectroscopy and Xrd-Microdiffraction. Condensed Matter and Interphases, 2013, v. 15(3), c. 224231. URL: http://www.kcmf.vsu.ru/resources/t_15_3_ 2013_002.pdf
35. Fattibene P., Carosi A., Coste V.D., Sacchetti A., Nucara A., Postorino P., Dore P. A comparative EPR, infrared and Raman study of natural and deproteinated tooth enamel and dentin. Physics in Medicine and Biology, 2005, v. 50(6), pp. 1095. DOI: 10.1088/00319155/50/6/004

36. Seredin P., Goloshchapov D., Kashkarov V., Ippolitov Y., Bambery K. The investigations of changes in mineral-organic and carbon-phosphate ratios in the mixed saliva by synchrotron infrared spectroscopy. Results in Physics, 2016, v. 6, pp. 315-321. DOI: 10.1016/j.rinp.2016.06.005

37. Goloshchapov D. L., Kashkarov V. M., Rumyantseva N. A., Seredin P. V., Lenshin A. S., Agapov B. L., Domashevskaya E. P. Synthesis of nanocrystalline hydroxyapatite by precipitation using hen's eggshell // Ceramics International, 2013, v. 39(4), pp. 4539-4549. DOI: 10.1016/j.ceramint.2012.11.050

38. Goloshchapov D. L., Lenshin A. S., Savchenko D. V., Seredin P.V. Importance of defect nanocrystalline calcium hydroxyapatite characteristics for developing the dental biomimetic composites. Results in Physics, 2019, v. 13, pp. 102158. DOI: 10.1016/j. rinp.2019.102158

39. Nanci A. Ten Cate's Oral Histology: Development, Structure, and Function. 8th ed., Elsevier Health Sciences, 2013, $400 \mathrm{p}$.

40. Ippolitov Ju. A. Vozmozhnost' povyshenija biologicheskoj tropnosti svetootverzhdaemoj bondingovoj sistemy dlja adgezii tverdyh tkanej zuba $\mathrm{k}$ plombirovochnomu material [The possibility of increasing the biological tropism of the light-curing bonding system for adhesion of hard tooth tissues to the filling material]. Volgogradskij nauchno-medicinskij zhurnal, 2010, v. 4 (28), pp. 31-34. URL: https://www. volgmed.ru/uploads/journals/articles/1293119124bulletin-2010-4-815.pdf

41. Seredin P., Goloshchapov D., Prutskij T., Ippolitov Y. Phase Transformations in a Human Tooth Tissue at the Initial Stage of Caries. PLoS ONE, 2015, v. 10(4), pp. 1-11. DOI: 10.1371/journal. pone.0124008

42. Seredin P. V., Goloshchapov D. L., Prutskij T., Ippolitov Yu. A. A Simultaneous Analysis of Microregions of Carious Dentin by the Methods of Laser-Induced Fluorescence and Raman Spectromicroscopy. Optics and Spectroscopy, 2018, v. 125(5), pp. 803-809. DOI: 10.1134/S0030400X18110267

43. Seredin P. V., Goloshchapov D. L., Prutskij T., Ippolitov Yu. A. Fabrication and characterisation of composites materials similar optically and in composition to native dental tissues. Results in Physics, 2017, v. 7, pp. 1086-1094. DOI: 10.1016/j.rinp.2017.02.025 
Середин Павел Владимирович - д. ф.-м. н., с. н. с., кафедра физики твердого тела и наноструктур, Воронежский государственный университет, Воронеж, Российская Федерация; e-mail: paul@phys.ru. ORCID iD 0000-0002-6724-0063.

Голощапов Дмитрий Леонидович - к. ф.-м. н., ведущий инженер, кафедра физики твердого тела и наноструктур, Воронежский государственный университет, Воронеж, Российская Федерация; e-mail: goloshchapov@phys.ru. ORCID iD 0000-0002-1400-2870.

Никитков Кирилл Андреевич - бакалавр, кафедра физики твердого тела и наноструктур, Воронежский государственный университет, Воронеж, Российская Федерация.

Бартенев Владислав Николаевич - бакалавр, кафедра физики твердого тела и наноструктур, Воронежский государственный университет Воронеж, Российская Федерация.

Кашкаров Владимир Михайлович - к. ф.-м. н., н. с., кафедра физики твердого тела и наноструктур, Воронежский государственный университет, Воронеж, Российская Федерация; e-mail: vmkashkarov@gmail.com. ORCID iD 0000-00019460-9244.

Ипполитов Юрий Алексеевич - д. м. н., профессор, зав. кафедрой стоматологии института последипломного медицинского образования, Воронежский государственный медицинский университет им. Н. Н. Бурденко Воронеж, Российская Федерация; e-mail: dsvgma@mail.ru. ORCID iD 0000-0001-9922-137X.

Jitraporn (Pimm) Vongsvivut - н. с., Австралийский синхротрон, Мельбурн, Австралия; e-mail: jitrapov@ansto.gov.au. ORCID iD 0000-0003-06993464.
Seredin Pavel V. - Dr. Sci. (Phys.-Math.), Senior Researcher, Department of Solid State Physic and Nanostructures, Voronezh State University, Voronezh, Russian Federation; e-mail: paul@phys. ru. ORCID iD 0000-0002-6724-0063.

Goloshchapov Dmitry L. - Cand. Sci. (Phys.Math.), Chief Engineer, Senior Researcher, Department of Solid State Physic and Nanostructures, Voronezh State University, Voronezh, Russian Federation; e-mail: goloshchapov@phys.ru. ORCID iD 0000-0002-1400-2870.

Nikitkov Kirill A. - Bachelor of Science, Department of Solid State Physic and Nanostructures, Voronezh State University, Voronezh, Russian Federation.

Bartenev Vladislav N. - Bachelor of Science, Department of Solid State Physic and Nanostructures, Voronezh State University, Voronezh, Russian Federation.

Kashkarov Vladimir M. - Cand. Sci.(Phys.-Math.), Senior Researcher, Department of Solid State Physic and Nanostructures, Voronezh State University, Voronezh, Russian Federation; e-mail:vmkashkarov@ gmail.com. ORCID iD 0000-0001-9460-9244.

Ippolitov Yury A. - Dr. Sci. (Med.), Full Professor, Head of Dentistry Institute of Postgraduate Medical Education Department, Voronezh State Medical University, Voronezh, Russian Federation; e-mail: dsvgma@mail.ru. ORCID iD 0000-00019922-137X.

Jitraporn (Pimm) Vongsvivut - Beamline Scientist, IR Microspectroscopy, Australian Synchrotron, Synchrotron Light Source Australia Pty LTD, Melburn, Australia; e-mail:jitrapov@ansto.gov.au.ORCID iD 0000-0003-0699-3464. 